\title{
Doente de Brasil: uma análise tillichiana da situação atual no Brasil
}

\author{
Pablo Fernando Dumer
}

\section{RESUMO}

Este artigo se propõe a analisar a situação atual do Brasil inserindo-se no processo vivo de reflexão, questionamento e reação às consequências sociais e antropológicas do momento político e econômico contemporâneos. Para isso, parte inicialmente da reflexão da escritora Eliane Brum acerca da corrosão das relações desde o conceito de autoverdade e dialoga com a teologia da cultura de Paul Tillich, seu contexto e as chaves teológicas, buscando inspiração e energia para o papel da teologia e da religiosidade no processo de articulação de resposta, reafirmação e resistência à diluição da verdade. Como pesquisa bibliográfica, visita artigos de Brum e obras de Tillich para atualizar a teologia da cultura do contexto e situação atuais do Brasil.

Palavras-chave: Paul Tillich; Eliane Brum; Ansiedade; Verdade; Teologia da Cultura.

\section{SICK OF BRAZIL: A TILLICHIAN ANALYSIS OF BRAZIL CURRENT SITUATION}

\section{ABSTRACT}

This paper aims to analyze Brazil current situation as part of a reflection living process. It asks and reacts to the social and anthropological consequences of the contemporary political and economic moment. For this, the paper starts with the writer Eliane Brum on the corrosion of relations from the concept of self-truth and dialogues with Paul Tillich's theology of culture, its context and theological keys, seeking inspiration and energy for the role of theology and religiosity in the process of articulating response, reaffirmation and resistance to the dilution of truth. As a bibliographic research, it visits Brum's writings and Tillich's works to update the theology of culture of Brazil's current context and situation. Key-Words: Paul Tillich; Eliane Brum; Anxiety; Truth; Theology of Culture. 


\section{Considerações iniciais}

O ano de 2019 inicia um novo período político da história do Brasil, o primeiro ano de mandato de um governo após uma conturbada eleição e pré-eleição, marcadas por atentado contra um candidato à presidência, o vitorioso, e a prisão do que era então líder das pesquisas de intenções de voto, além de polarização acirrada, inclusive fora do espaço público adentrando o espaço privado das famílias. A vitória de um dos lados e ascensão deste ao governo não pacificou o clima polarizado, mas mantém o clima de campanha, com falas controversas, discursos agressivos e uma sequência de crises, sejam internamente ou mesmo internacionalmente.

O cenário que se pinta, já há muitos anos, é de constante agitação, incerteza e, paradoxalmente, paralisia. Não se trata de uma novidade. A incerteza existencial, a agitação "pós-moderna" das mudanças constantes, do mundo em estado líquido, é observado já há muitos anos, por diferentes pensadores em diferentes contextos e situações. Mas, conforme também observado por Hartmut Rosa (ROSA, 2016, p. 13), e já era previsto, ocorre uma aceleração da incerteza e esta aceleração desvela-se em 2019.

Para empreender a difícil tarefa de analisar a situação contemporânea brasileira refletiremos inicialmente a partir de textos da colunista Eliane Brum e, em seguida, discutiremos os temas a partir da teologia de Paul Tillich. O presente artigo não se situa distante do objeto que se propõe a analisar, mas se insere no processo vivo de reflexão, questionamento e reação ao contexto atual do Brasil e suas consequências para a teologia e quaisquer outras disciplinas afetadas pela situação existencial do ser humano. O artigo também celebra os 100 anos da teologia da cultura de Tillich revisitando o contexto na qual ela nasce e buscando inspiração nela para a teologia contemporânea.

\section{O Brasil doente sob análise}

A escritora, colunista, documentarista Eliane Brum em agosto deste ano publicou um artigo no jornal El País sob o título Doente de Brasil: Como resistir ao adoecimento num país (des)controlado pelo perverso da autoverdade. $\mathrm{O}$ artigo presta uma reflexão sobre o momento atual do Brasil. Trata-se de um estudo de caso e coleta de depoimentos de quem 
está na linha de frente do enfrentamento do problema dos frequentes casos de ansiedade e depressão no Brasil contemporâneo e, dessa forma, torna-se um dos textos-chave para a análise de conjuntura nacional em contexto global da atualidade.

O adoecimento do país, conforme Eliane Brum, é um fenômeno que pode

ser notado nos consultórios nos últimos anos de polarização política, que dividiu famílias, destruiu amizades e corroeu as relações em todos os espaços da vida, ao mesmo tempo em que a crise econômica se agravava, o desemprego aumentava e as condições de trabalho se deterioravam (BRUM, 2019).

Observa-se não só um fenômeno de conturbação política, mas este se manifesta na corrosão das relações sociais em diferentes níveis da vida humana, até mesmo nas mais imediatas como a família. Essa corrosão do campo das relações é agravada pela corrosão das condições materiais de sustentação da vida em consequência da crise econômica, precarização do trabalho e crescimento do desemprego no país. Segundo a colunista, esse fenômeno foi acirrado pela campanha eleitoral de 2018 que não só ecoa no, mas é usado como tática e estratégia de governo do lado político vitorioso em 2018.

A colunista recorda um post viralizado do psiquiatra Fernando Tenório de 10 de julho de 2019, no qual relata o atendimento de "um homem de 45 anos, negro, sem escolaridade" que expôs a insegurança causada pelo desemprego e a precarização do trabalho daí decorrente. O paciente expôs também o "medo de ser o próximo da fila" do desemprego. Para o psiquiatra: "Tem sintomas de esgotamento que descambam para ansiedade. Qual o diagnóstico para isso? Brasil. Adoeceu de Brasil" (BRUM, 2019).

$\mathrm{O}$ artigo de Eliane Brum volta a citar o psiquiatra:

"Para a psiquiatria, a depressão é a tristeza sem contexto. Ou seja, ela é relacionada à estrutura psíquica de cada pessoa, às fundações e alicerces construídos na infância", explica. "O que temos vivido hoje nos consultórios é o aumento da depressão com contexto, esta que não tem a ver com a estrutura do indivíduo e que nem vai melhorar no divã. Esta em que o uso de medicamentos só vai servir para obscurecer o esclareci- 
mento das questões. Esta que só pode ser sanada por mudanças sociais (BRUM, 2019)."

A agitação e incerteza da situação atual também causa paralisia, sintoma da ansiedade. Ela decorre em grande medida do sentimento de impotência diante do que está acontecendo. Segundo Brum, referenciando-se a uma psicanalista anônima:

As pessoas, hoje, não sabem como reagir à quebra do pacto civilizatório representada pela eleição de uma figura violenta como Bolsonaro, que não só prega a violência como violenta a população todos os dias, seja por atos, seja por aliar-se a grupos criminosos, (...) seja por mentir compulsivamente. Não sabem, também, como parar essa força que as atropela e esmaga. (...) E então passam a sentir-se como reféns - e, seguidamente, a atuar como reféns (BRUM, 2019).

A paralisia advém da impotência e da incerteza. As referências de reação, próprias de todo processo dialogal, a resposta à situação são quebradas pelo totalmente novo e irreferenciado do rompimento dos pactos sociais estabelecidos e do rompimento com a verdade, tal como classicamente se entendia, uma vez que a figura autoritária recorre à sua própria verdade, que passa a ser indiscutível, porque o interlocutor nem sequer possui parâmetros para entender a autoverdade, que para ele é uma heteroverdade: ele está excluído dela.

A dificuldade da análise da situação atual do Brasil está no caráter implícito dos seus problemas. Vítimas e sobreviventes do nazismo ou da ditadura militar brasileira, por exemplo, lidavam com o mal expresso, explícito. O modus operandi do momento atual do Brasil é outro, não por isso menos violento. Para Brum, o que essa violência que faz adoecer "tem demonstrado é o quanto pode ser difícil resistir (também) à violência do cotidiano, aquela que se infiltra nos dias, nos pequenos gestos, na paralisia que vira um modo de ser, nas covardias que deixamos de questionar" (BRUM, 2019). A violência atual é implícita e constante, é cotidiana, e por isso tem a tendência a ser normalizada.

Essa paralisia se expressa na autocensura, nos atos de preservação à exposição e desgaste de se opor e resistir. Nos termos da autora, se expressa como "conformação", "silêncio", "ausência". Não se trata em momento algum de uma covardia como falha moral, mas uma reação 
normal de autopreservação. Contudo, não se pode deixar de observar que esse mecanismo de autopreservação contribui para o estabelecimento do autoritarismo. Para Eliane Brum, "é também assim que se adoece uma população por aquilo que ela já tem medo de fazer, porque antecipa o gesto do opressor e se cala antes de ser calada" (BRUM, 2019).

$\mathrm{O}$ que se experiencia, como a autora tem explanado no decorrer do seu artigo, é que essa autocensura e por isso conformação ao invés de resistência, se dá porque essa pessoa já não encontra lugar próprio na qual sua existência, por um lado, está preservada e, por outro lado, pode transitar e se articular. A figura autoritária coloniza todos os espaços. Brum assim expressa essa experiência:

Um dos sintomas do cotidiano de exceção que vivemos é a colonização de nossas mentes. Mesmo pessoas que viveram a ditadura militar não têm recordação de algum momento da sua vida em que tenham pensado todos os dias no presidente da República. Bolsonaro administra o horror dos dias, com suas violências e mentiras, de um modo que o torna onipresente. Faça o teste: quantas horas você consegue ficar sem pensar em Bolsonaro, sem citar uma bestialidade de Bolsonaro? É isso o autoritarismo. Mas sobre isso poucos falam (BRUM, 2019).

A figura autoritária pode até não ter logrado até o presente momento uma ditadura de facto, mas tem logrado um discurso autoritário, uma narrativa de eliminação do diferente e de negação de qualquer questionamento e oposição. A colunista cita o psicanalista e escritor Mario Corso: "Bolsonaro usa aquilo que você", isto é, a autora Eliane Brum, "definiu como autoverdade para antecipar a ditadura. Os fatos não importam, o que 'eu' digo é o que é” (BRUM, 2019).

A autora já havia escrito a respeito do tema em julho de 2018, também no El País. Na ocasião ela afirmou:

A pós-verdade se tornou nos últimos anos um conceito importante para compreender o mundo atual. Mas talvez seja necessário pensar também no que podemos chamar de "autoverdade". Algo que pode ser entendido como a valorização de uma verdade pessoal e autoproclamada, uma verdade do indivíduo, uma verdade determinada pelo "dizer tudo" da internet (BRUM, 2018). 
O que determina o valor desta "verdade" não são os fatos, nem o conteúdo, mas o ato de "dizer tudo". Trata-se de um fenômeno que beneficiou e beneficia tanto Bolsonaro como Donald Trump. Para a autora: "Se o valor está no ato de dizer e não no conteúdo do que é dito, não há como perceber que não há nenhuma verdade no que é dito" (BRUM, 2018). O determinante da autoverdade não está no seu conteúdo, na sua referência aos fatos, na possibilidade de observação universal, coletiva, mas no ato em si e no ato do locutor, ou seja, algo não é verdade porque o interlocutor também pode concluir a verdade, mas porque o locutor afirma ser verdade.

O fenômeno da autoverdade corrompe o espaço político como lugar de diálogo, debate, para a verdade do um, do indivíduo, mas não de qualquer indivíduo. O diálogo, assim, desaparece para dar lugar ao discurso daquele que tem o poder de dizer, de ditar, o ditador. Para legitimar-se, essa autoverdade traveste-se de uma teologia, especialmente no que diz respeito a uma luta do bem contra o mal, ou seja, de maniqueísmo. Como tal, a autoverdade do autoritário e a teologia batalhista retroalimentam-se.

A análise da situação da angústia contemporânea do Brasil precisa passar não só pela análise das condições materiais, mas das espirituais do contexto brasileiro. Conforme Brum:

Figuras como Bolsonaro se beneficiam da crise econômica, do crescimento da violência e da produção de medo, sim. Mas sua força vem de uma população treinada para aderir pela fé ao que não diz respeito à fé. Por isso é possível até mesmo fazer política e se dizer apolítico. Se o imperativo é crer, a adesão já está garantida não importa o conteúdo do discurso, desde que a dramaturgia garanta entretenimento, espetáculo. Embora pareçam desacreditar de quase tudo em suas manifestações na internet, ninguém se iluda. Uma parte significativa do eleitorado brasileiro é formada por crentes. E ser crente hoje no Brasil tem um sentido e um alcance muito mais amplo do que em qualquer momento da história do país (BRUM, 2018).

O rompimento da possibilidade da verdade através do diálogo e do debate aliena do ser humano a possibilidade de resposta, de articulação de resistência, de reafirmação de seu estado como ser, seu valor 
e seu papel. A colunista cita o professor de psicanálise da USP, Rinaldo Voltolini, que disse:

Este é um grande disparador do sofrimento das pessoas, ao constatarem que estão fora no nível mais importante. (...) você está fora das possibilidades de leitura do mundo. O que você diz não tem valor, não tem sentido, não tem significado. É como se, de repente, você já não tivesse lugar na gramática (BRUM, 2019).

Para sair de termos abstratos, a exclusão da pessoa comum do círculo da verdade manifesta-se concretamente na subtração de direitos trabalhistas e sociais. Nessa situação, o trabalhador, o opositor político ou a pessoa de minoria, não tem possibilidade de resposta, mas é refém de um discurso, uma ordem, uma vontade alheia a ela. Isso é fenômeno concreto da destruição da verdade como diálogo.

Voltolini ainda conclui no artigo de Eliane Brum:

Não é que estamos vivendo o mal-estar na civilização. Isso sempre houve. A questão é que, para ter mal-estar é preciso civilização. E hoje, o que está em jogo, é a própria civilização. Isso não é da ordem do mal-estar, mas da ordem do horror (BRUM, 2019).

A pergunta que se chega é como enfrentar o processo de destruição da civilização vista por Brum e Voltolini, por exemplo. Nas palavras de Brum: "Como barrar o adoecimento provocado pela destruição da palavra como mediadora?". A resposta de Voltolini lembra dois pensadores judeus do século passado, Einstein e Freud: "Quando Einstein pergunta a Freud como seria possível deter o processo que leva à guerra, Freud responde que tudo o que favorece a cultura combate a guerra" (BRUM, 2019).

Se há favorecimento de setores eclesiásticos e teológicos à destruição da palavra mediadora, então há desprezo desses mesmos setores à cultura. Os insights tillichianos que a explanação da autora Eliane Brum nos leva são muitos, sobre o problema da angústia, sobre a verdade e sobre a cultura. A seguir visitaremos, de maneira breve, estes temas na obra de Tillich e investigaremos como sua teologia pode nos ajudar na leitura da realidade brasileira contemporânea e suscitar energia teológica para o enfrentamento dos problemas até aqui elencados. 


\section{As tempestades sob análise de Paul Tillich}

$\mathrm{Na}$ condição de emigrado aos EUA por conta da ascensão do nazismo na Alemanha, Tillich reflete em plena Segunda Guerra Mundial os processos históricos que levaram àquele momento. Para entender essa reflexão são importantes dois artigos presentes no livro A Era Protestante. O primeiro, de 1943, trata da desintegração que levou à Segunda Guerra e o segundo, de 1942, trata da reconstrução espiritual do pós-guerra. Trata-se de artigos escritos na condição de refugiado, na condição de não pertencer plenamente ao novo contexto, país, cultura e época, e nem mesmo pertencer mais ao antigo do qual foi expurgado. É uma condição que Tillich chamará de "fronteira" (TILLICH, 1992, p. 253). Ao analisar a situação que o mundo havia chegado naquela época, Tillich despersonaliza o problema, ou seja, na verdade ele está ultrapassando a simploriedade de acusar Hitler pelo mal da guerra e observando os elementos colocados pela história que geraram tanto a guerra como Hitler. Diz Tillich:

Pressuponho que as tempestades desta época não são mero acidente causado por pessoas de mau caráter, que não teriam acontecido se tais pessoas não tivessem existido. Nenhuma pessoa má é capaz de fazer a história a não ser que o terreno já esteja preparado em grande escala (TILLICH, 1992, p. 254).

Para o teólogo da fronteira, portanto, os acontecimentos que ele estava testemunhando eram resultado "de forças estruturais da sociedade burguesa do século dezenove e do começo do vinte" (TILLICH, 1992, p. 254). Havia, na observação de Tillich, uma espécie de revolução na época a nível mundial, uma revolução que marcava o fim da sociedade do século passado para um novo tipo de sociedade. Nas palavras do teólogo:

É possível descrever o caráter geral da transformação revolucionária que vivemos agora, da seguinte maneira: a partir da derrocada da harmonia natural ou automática em que baseava o sistema de vida dos séculos dezoito e dezenove, procura-se, agora, um outro sistema de vida e pensamento baseado numa unidade intencional e planejada, abrangendo todos os domínios da existência (TILLICH, 1992, p. 255). 
Um dos elementos que constituíam a derrocada do antigo sistema era a crise capitalista vivida após Primeira Guerra. Tillich faz uma análise precisa do desenvolvimento do capitalismo que se desenvolveu de um contexto de "inúmeras pequenas empresas que competem entre si de maneira comparativamente livre" (TILLICH, 1992, p. 255). Esse é o elemento básico do liberalismo econômico. Acontece que o gradual desenvolvimento capitalista gerou concentração de renda, o "monopólio". Essa foi a receita para a crise:

Os grandes investimentos feitos pelas empresas de monopólio só seriam rentáveis numa economia em expansão. Quando a expansão se acabou (...) os investimentos deixaram de dar suficiente lucro, e a crise (...) foi-se perpetuando. A competição, assim dificultada, obrigou o emprego de todos os meios de progresso técnico, produzindo, por sua vez, mais desemprego, ao mesmo tempo em que reduzia o poder aquisitivo das massas e aprofundava a crise (TILLICH, 1992, p. 256).

Tillich compreendia, contudo, que para além das consequências materiais da crise econômica estavam as consequências psicológicas que a crise gerava sobre a população. Para ilustrar esse problema, Tillich recorre a um caso:

Nada é pior do que a situação de desemprego permanente. Os trabalhadores que passaram pelos bombardeios de Londres nos dizem que a ameaça de desemprego é pior do que a ameaça da morte. Os desempregados não são apenas, como qualquer trabalhador no capitalismo, certa quantidade de força de trabalho capaz de ser comprada ou vendida; representam uma força de trabalho incapaz de ser aproveitada. O pior elemento presente em tal situação não é a miséria econômica resultante do desemprego, mas o sentimento da absoluta falta de sentido (TILLICH, 1992, p. 256).

A crise do sistema capitalista provoca a precarização do trabalho e essa significa a precarização do trabalhador, que não é só força de trabalho, mas um ser humano em busca de sentido e realização de suas potencialidades. A precarização do trabalhador significa em última instância a espoliação do ser humano de seu sentido. Trata-se de um problema antropológico. A respeito desta precarização do ser humano, Tillich comenta: 
Quando os seres humanos percebem que o destino humano lhes foi retirado das mãos, e que são jogados na rua por processos objetivos em que não participam, inseridos numa grande máquina como partes e instrumentos do amanhã, capaz de lhes conduzir à destruição, depois de amanhã, não se pode esperar outra coisa a não ser desespero (TILLICH, 1992, p. 277).

Para Tillich, o capitalismo coisifica o ser humano, mas não apenas como força de trabalho, mas também como recipiente de consumo. Para tal, essa coisificação não é apenas lograda pela conformação do trabalho, mas é ideológica, cultural, é atingida pela conformação através dos bens culturais, bem como pelo sistema educacional (TILLICH, 1992, p. 277). O que Tillich observa na década de quarenta, é como os veículos de comunicação em massa e os produtos culturais, como o cinema, jornal, etc, formatam o ser humano para dentro de uma sociedade orientada, tão somente, para produção e consumo de bens, na qual o senso de pertencimento e dever da comunidade tendem a desaparecer.

Em Teologia da Cultura, Tillich comenta mais sobre essa coisificação e conformação humana pelo sistema de produção e consumo:

Achamos que somos mestres do mundo e de nós mesmos. Mas, na verdade, fazemos parte da realidade que criamos, objetos entre objetos, coisas entre coisas, parte da engrenagem da máquina universal, à qual devemos nos adaptar para que ela não nos esmague. Essa adaptação nos transforma em meios para fins que também, por sua vez, são meios, sem finalidade alguma. Resultam daí experiências de vazio e falta de sentido, de desumanização e alienação (TILLICH, 2009, p. 87).

Desta forma, é possível concluir como a análise do desenvolvimento e crise do capitalismo precisa ser feita pelo viés antropológico, ou seja, de como atinge o ser humano. O desenvolvimento do "monopólio" e sua crise é uma força que esmaga o ser humano como um sacrifício. Em outras palavras:

O ser humano, lançado para todos os lados pela força anônima do culto capitalista de Deus ausente, é como uma vítima sacrificial. A percepção do ser humano quanto a esse processo é de frustração, o que só aumenta seu vazio, cujo espaço o capitalismo pretende preencher com mais bens e símbolos descartáveis, sem aspecto de transcendência e eternidade. Apesar de sua desumanização, o ser humano é ainda humano o suficiente para 
sentir sua desumanização. Essa angústia é um recurso de sua superação (STUMPF et DUMER, 2018, p. 55).

Tillich prossegue em sua análise para outra etapa, isto é, na qual o Estado interfere na crise do capitalismo liberal para salvar o sistema monopolista mediante a socialização das perdas (TILLICH, 1992, p. 256). A etapa seguinte, e final do ponto de vista da observação de Tillich, tratava-se do fascismo e do capitalismo estatal (TILLICH, 1992, p. 257).

A corrosão do sistema econômico atinge também a política e corrói a democracia. Na concepção do teólogo, “democracia não é um conceito político in abstracto", mas pressupõe certos desenvolvimentos históricos e culturais, como "certa base de concordância entre os partidos", além de "boa dose de confiança nos representantes votados pelo povo" (TILLICH, 1992, p. 258). Sem isso, o sistema democrático entra em crise e foi justamente o que aconteceu em muitos países no contexto entre-guerras. Na Europa da virada do século XIX e XX ocorrera a desintegração do sentimento e senso comum unificador dos indivíduos (TILLICH, 1992, p. 259-260) nas democracias liberais e, com isso, testemunharam a ascensão de regimes totalitários.

Para Tillich, o acirramento dos contrastes sociais pela crise do capitalismo liberal e a constituição dos monopólios, tornou impossível a harmonia pretendida pelo iluminismo e a desintegração social começou. Os contrastes sociais diluíram a liga que sustentava tanto o polo da personalidade como da comunidade (TILLICH, 1992, p. 276), isto é, da individualidade e da coletividade do ser humano. A desintegração da relação entre personalidade e comunidade, Tillich observa como um desenvolvimento que começa no final da Idade Média, quando o protestantismo e o renascentismo romperam com os elementos transcendentais que firmavam essa relação, porém ainda mantinham certa relação. Ela deteriorou-se no desenvolvimento da modernidade e do capitalismo: "A comunidade cedia o lugar para a cooperação com propósitos definidos; a personalidade transformava-se na quantidade da força de trabalho ou na inteligência ou ajustamento técnico" (TILLICH, 1992, p. 279). O final desse desenvolvimento, na época de Tillich, era o fascismo.

A situação cultural na Europa que antecedeu a ascensão de Hitler e outros regimes fascistas é descrita por Tillich em quatros caracterís- 
ticas. A primeira delas é o medo ou "ansiedade indefinida". Conforme o teólogo: "Tinha-se a impressão de que não havia mais segurança econômica, política, cultural e religiosa (...) era melhor a autoridade com segurança do que a liberdade com medo!” (TILLICH, 1992, p. 260). A segunda característica que se somava ao sentimento de insegurança era a angústia frente à incerteza. Especialmente as novas gerações, a juventude "queria certezas a qualquer preço, mesmo se fossem a completa heteronomia e a submissão a um líder" (TILLICH, 1992, p. 260). A terceira característica era justamente da solidão que decorria da desintegração social e cultural do individualismo tardio. A solidão potencializa os sentimentos de ansiedade e incerteza das características anteriores. A busca da juventude da época anterior ao nazi-fascismo buscava por formas de superar a solidão, por novas comunidades (TILLICH, 1992, p. 261). Isso nos leva à quarta e principal característica.

Para Tillich essa quarta e principal característica da desintegração social e cultural da sociedade burguesa era a falta de sentido e o cinismo diante da vida. Segundo a análise de Tillich:

Não foram apenas os símbolos religiosos do passado que perderam o poder de dar sentido à vida, mas também os símbolos filosóficos e políticos que pretendiam substituí-los. Não sobrou elemento algum capaz de inspirar entrega e devoção absoluta. Mas era isso que a juventude buscava. Queria símbolos fortes, indiscutíveis e exigentes. Procurava símbolos religiosos - e, na sua falta, símbolos quase religiosos. Sem eles, os jovens, mas não apenas os jovens, não achavam sentido na vida. $\mathrm{O}$ ceticismo e o cinismo conquistam o espírito e abrem os corações para a recepção dos símbolos 'demoníacos'. Os que conseguem construir tais símbolos facilmente se transformam em líderes, e o cinismo não fica longe do fanatismo (TILLICH, 1992, p. 261).

Se for possível traçar paralelos entre a análise da desintegração da época de Tillich com a desintegração de nossos dias, então precisamos retomar o significado da ansiedade que toma conta da experiência pessoal e coletiva do Brasil nos últimos anos e que não dá sinais de afrouxamento. A categoria com qual podemos traçar diálogo é a ansiedade. Ansiedade, para Tillich, significa a consciência do "não-ser", isto é, da negação do ser (TILLICH, 1972, p. 28). A ansiedade é o estado do ser humano diante de uma situação para a qual não existe ou não 
visualiza alguma solução (TILLICH, 1972, p. 30). Sobre esse tema Tillich trabalha no seu livro A Coragem de Ser.

No livro, Tilich identifica três tipos de ansiedade: a ôntica, ou seja, a ansiedade frente ao destino e à morte, a espiritual que é a ansiedade frente à vacuidade e à insignificação, e a ansiedade moral frente à culpa e à condenação. Podemos identificar os três tipos de ansiedade no momento atual do Brasil e mesmo do mundo. De maneira global, a ameaça ôntica se faz presente no cenário de colapso climático e na constante ameaça do desemprego, precarização do trabalho, bem como pela ameaça da violência. A ansiedade moral, que Tillich identifica surgida pela impacto da mensagem judaico-cristã de pecado (TILLICH, 1972, p. 45) retorna ao espaço público não-secularizado do Brasil pela moralização da política ou pela militância religiosa (especialmente evangélica) nos poderes políticos, que pauta especialmente questões referentes a gênero e temas afins. Mas a ansiedade espiritual (e não confundir espiritual com o religioso/místico) ${ }^{1}$ é o tipo especial a ser observado.

O não-ser experimentado pela ansiedade espiritual é aquele que nega a vivência criadora do ser humano nas esferas de significação (TILLICH, 1972, p. 36). As esferas de significação são coletivas, são espaços de participação do indivíduo na sociedade, são formas e processos de participação. A ansiedade espiritual é a experiência da corrosão das relações de significação. A decepção com o espaço relacional, o vazio do cinismo que oportuniza o fanatismo que decorre da corrosão ou desintegração é o grande problema antropológico para o qual a teologia é desafiada a responder.

Tillich expressa assim o problema:

somos cortados da participação criadora numa esfera de cultura, nos sentimos frustrados a respeito de algo que se tinha afirmado com paixão, somos conduzidos da devoção a um objeto à devoção por outro e de novo por outro, porque o sentido de cada um deles se desvanece e o eros criador se transformou em indiferença ou aversão. Tudo é tentado e nada satisfaz (TILLICH, 1972, p. 37).

Em alemão, o adjetivo é geistig que não possui significado de espiritualidade (onde seria mais apropriado usar o adjetivo geistlich), mas de intelectualidade, ou possivelmente seja melhor traduzi-lo como noético como já o fizemos anteriormente na pesquisa de mestrado: DUMER, 2017, p. 65. 
Trata-se do sentimento de esgotamento das possibilidades de enfrentamento do problema, bem como a perda de fé em novas possibilidades. Tillich chama isso de "dúvida total", ou seja, a separação do ser humano do todo e o seu isolamento (TILLICH, 1972, p. 38). Acima no artigo chamamos isso de "paralisia" em decorrência da falta de referência pelo esvaziamento de significados estabelecidos e imposição autoritária de significados com os quais o interlocutor não possui relação, participação, fenômeno esse chamado pela colunista Eliane Brum de "autoverdade".

Essa corrosão da participação nos processos de significação, como já dissemos, destrói as esferas de relação, destrói o diálogo e o debate, destrói a possibilidade de oposição e articulação de resistência. Nem mesmo é possível interpretar esse problema como uma questão abstrata, intelectual. Essa corrosão parte e traz consigo problemas materiais. A mesma observação Tillich também faz: "As auto-afirmações ôntica e espiritual precisam ser distintas, mas não podem ser separadas. $\mathrm{O}$ ser do homem inclui sua relação com as significações" (TILLICH, 1972, p. 39). E mais que isso. A análise tanto de Brum do contexto contemporâneo do Brasil como de Tillich do processo de desintegração do ocidente que antecedeu o fascismo, demonstra que a corrosão das relações parte da corrosão das condições de vida, de trabalho, de convivência e então retornam gerando mais deterioração ainda. Jorge Pinheiro em seu estudo sobre Tillich destaca que "na história, uma ruptura espiritual vem sempre associada a uma ruptura econômica" e "um processo de unidade espiritual vem associado a um processo de unidade econômica" (PINHEIRO, 2017, p. 59). A seguir refletiremos sobre a responsabilidade da teologia frente a esse problema.

\section{Cura e o processo de reconstrução do que perdemos}

Para a colunista Eliane Brum: "O desafio imposto tanto pela pós-verdade quanto pela autoverdade é como devolver a verdade à verdade" (BRUM, 2018). Esse processo de devolução da verdade é árduo e complexo. Inclui, certamente, reconduzir a verdade à vítima, ao ser humano preso em ansiedade, reconduzi-lo a si mesmo, uma vez que a ansiedade é a alienação do ser perdido entre as coisas. Significa um processo de "terapia" coletiva. O processo de cura do Brasil doente 
parte de reconduzir as pessoas a si. Esse processo de reconstrução espiritual também é entendido por Tillich:

Faz sentido levar as pessoas a entender onde estão; que lhes falta; que lhes aconteceu; que perderam; e porque se sentem sozinhas, inseguras, ansiosas, sem propósitos mais altos, sem a preocupação suprema, sem o verdadeiro eu, e sem o mundo real (TILLICH, 1992, p. 280).

Em termos do momento atual do Brasil significa uma profunda análise de conjuntura sobre os problemas sociais que conduzem à crise política e de como esse atinge de volta a vida social e pessoal. Sem essa análise de ida e volta não é possível reaver as fissuras da individualidade e da coletividade que permitem as rupturas. Por isso, além de reconduzir as pessoas a si é preciso romper o isolamento do eu, das identidades em jogo e principais atingidas pela negação do diálogo, da voz, da existência. Este talvez seja um dos maiores desafios. Reconduzir a pessoa do estado alienante de ser coisa entre coisas, ao mesmo tempo em que rompe o isolamento autocentrado para o encontro com o outro e o confronto, diálogo daí decorrente é também o caminho percorrido por Tillich em A Coragem de Ser. No livro, Tillich trata, em termos ontológicos e éticos, da ansiedade e trata três formas de coragem para enfrentar a ansiedade. As duas primeiras equivalem aos polos de individualidade e coletividade, ou seja, coragem como individualização e como participação.

O processo de cura, isto é, de reintegração, nasce do protesto da pessoa contra a sua coisificação no nível econômico, político, cultural (TILLICH, 1972, p. 107) e afirmar-se como ser individual com identidade. Tillich chama esse processo de individualização (TILLICH, 1972, p. 89). O outro polo do processo se chama de participação (TILLICH, 1972, p. 67). Só há “eu” porque há um “mundo" no qual o indivíduo participa e desenvolve sua potência de ser (TILLICH, 1972, p.69-70). Mas esses polos ficam sem profundidade e potência para enfrentar as ansiedades ôntica, moral e espiritual sem a transcendência. Para Tillich: "A coragem que incorpora em si esta tripla ansiedade", isto é, a ôntica, moral e espiritual, "precisa estar arraigada a uma potência de ser que seja maior do que a potência de um eu e a potência do seu mundo" (TILLICH, 1972, p. 122). De igual forma, não será possível 
superar a ansiedade do Brasil, a corrosão das relações, a corrosão da verdade e o adoecimento das pessoas apenas reconduzindo as pessoas a si e restabelecendo laços de diálogo. É preciso um poder restaurador que faça frente ao poder destruidor. Aqui a teologia possui papel na reconstrução espiritual da contemporaneidade.

Certamente não falta fé nem religião no Brasil, pelo contrário, há em demasia. Aqui o contexto do Brasil difere do contexto no qual Tillich refletiu e para o qual propôs. Contudo, é importante para a teologia resgatar a relação que Tillich fazia entre fé e dúvida. Num contexto de autoverdade dominante, a fé precisa trazer dúvida e não certeza. Tillich destaca que a palavra "fé" foi, mais que qualquer outra, "incompreendida, distorcida e mal definida". Para o teólogo a fé não pode ser fenômeno de se crer em algo inacreditável, mas é um estado, o estado de "estar possuído por aquilo que nos toca incondicionalmente" (TILLICH, 1974, 05). Mesmo essa definição de fé não estaria livre de descambar em fanatismo religioso não fosse o antídoto que o próprio Tillich oferece na Teologia Sistemática, ou seja, que fé precisa necessariamente estar aliada ao amor (TILLICH, 2011, p. 584). Fé e amor é reunir o que está separado (TILLICH, 2004, p. 36). O que Tillich compreende como fé não é a negação da dúvida, um ato de certeza autocentrado, uma autoverdade contra o mundo, mas a aceitação da dúvida como possibilidade criativa (TILLICH, 1974, p. 66).

Nesse sentido, o papel que se apresenta à teologia na superação do estado de ansiedade que a situação atual se encontra é de levantar o poder dialogal do encontro e da humildade diante da finitude das certezas, projetos e respostas. É preciso ainda assumir a responsabilidade enquanto teologia pelo cenário do Brasil, uma vez que o discurso político no poder hoje possui referência teológica. O campo de disputa está na teologia. É preciso reforçar o aspecto dialogal da teologia, especialmente a tillichiana, reforçar as correlações com as perguntas existenciais da população e retraduzir e reapresentar símbolos teológicos que respondam às mesmas (TILLICH, 2011, p. 23).

Tendo em vista a complexidade da situação teológica que vivemos é preciso prevenir-se à frustração. As realizações do ser são sempre para dentro das ambiguidades do não-ser, a coragem sempre é sustentada em meio à ansiedade, a verdade é proclamada em meio à dúvida, à mentira 
e à banalização. Por isso, retoma-se a importância da teologia de Tillich e de sua exposição sobre a ansiedade e a coragem, quando diz:

O ser tem o não-ser "dentro" de si mesmo, de modo que é eternamente presente superado no processo de vida divina. A base de tudo que é não é uma identidade morta, sem movimento e vir a ser; é uma criatividade vivente. Ele se afirma criadoramente, conquistando eternamente seu próprio não-ser (TILLICH, 1972, p. 27).

A coragem é o conceito tillichiano que incorpora a ansiedade para dentro de si e a supera num processo vivo, dinâmico e contínuo. Coragem é tomar a ansiedade para si, assumir a existência com suas distorções. Para Tillich, ali "onde a existência é mais radicalmente existência (...) é que a existência é vencida” (TILLICH, 2011, p. 409). A coragem "é o Sim à identidade ali onde está mais radicalmente negada" (DUMER, 2017, p. 116). A coragem é a forma de reafirmação da vida diante da morte, da liberdade diante da censura, da verdade como palavra mediadora diante da autoverdade autoritária. A coragem é um conceito teológico fundamental para os tempos que vivemos, "torna-se, assim, central para a antropologia teológica, justamente em um contexto de angústia, crise e terror da e na sociedade contemporânea" (DUMER, 2017, p. 123).

Retomamos e repetimos aqui ainda a frase final de $A$ Coragem de Ser: "A coragem de ser está enraizada no Deus que aparece quando Deus desapareceu na ansiedade da dúvida" (TILLICH, 1972, p. 146). O Deus acima de Deus de Tillich em nada se parece com o Deus acima de todos. Mas é o Deus que emerge quando os discursos a respeito de Deus, aliados do poder, caem. O termo "acima", portanto, não descreve o sentido. Mais apropriado seria a tradução "além". Deus além de Deus, o que só se revela e é experimentado quando a fé-poder cai ou é derrubada.

\section{Considerações finais}

Estamos vivendo o processo que descrevemos neste artigo. Novos elementos ainda surgirão para complexificar e conceder esclarecimento a respeito do que adoece política, economia, sociedade, antropologia e espiritualidade atuais. Contudo, novos elementos também surgirão de 
reafirmação daquilo que é negado, reafirmando que aquilo que pensou-se ter sido perdido ainda está presente, vivo e nas mãos dos que se sentem perdedores. A resistência assume-se em manifestações culturais, em atos significativos, já que, como Freud responde a Einstein: "tudo o que favorece a cultura combate a guerra" (BRUM, 2019).

A cura do estado contextual de ansiedade que se vive no Brasil se faz pela reafirmação de símbolos de identidade tanto individuais como coletivos. A resistência é assim um ato primariamente cultural. É preciso ter em mente que essa resistência será precária, pois é a resistência de pessoas precarizadas. Mas o próprio ato de reafirmação de símbolos já é em si um ato de superação desse estado de precariedade (DUMER, 2019, p. 97), é ato de reafirmação de sentido. A resistência afirma existência.

Para finalizar, ainda permanece para seguir a reflexão de como enfrentar a autoverdade, como devolver a verdade à sua condição libertadora expressa pelo evangelho de Jesus Cristo segundo João 8.32. Essa reflexão precisará fazer parte da agenda de teólogos, teólogas e pessoas de fé, mas ela pode encontrar ponto de partida em outro teólogo luterano que não Tillich. Vítor Westhelle em referência a Lutero e a teologia da cruz, defende uma teologia que fale a verdade, a parrésia, e a verdade como a "coisa como ela é" (WESTHELLE, 2008, p. 98). Isso significa uma teologia que investiga a situação e nomeia os elementos dessa situação da forma como são, sem tentar amortecer seu impacto. A teologia da verdade, e da verdade libertadora, fala inclusive contra si mesma: é cruz. Ela aponta para o que adoece e chama isso de doença. Ela assume essa verdade e por assumi-la é afirmação corajosa de sentido, de esperança e de resistência.

\section{Referências}

BRUM, Eliane. Bolsonaro e a autoverdade: Como a valorização do ato de dizer, mais do que o conteúdo do que se diz, vai impactar a eleição no Brasil. El País, 2018. Disponível em: https://brasil.elpais.com/brasil/2018/07/16/ politica/1531751001_113905.html. Acesso em: 04 out. 2019.

Doente de Brasil: Como resistir ao adoecimento num país (des)controlado pelo perverso da autoverdade. El País, 2019. Disponível em: https://brasil.elpais.com/brasil/2019/08/01/opinion/1564661044_448590.html. Acesso em: 04 out. 2019. 
DUMER, Pablo F. O ser humano entre a angústia e a coragem: uma antropologia teológica para a pós-modernidade. 2017. 128 p. Dissertação (Mestrado em Teologia) - Faculdades EST. São Leopoldo, Rio Grande do Sul.

The Protestant Principle and the Situation of the Precariat: a new Approach to Paul Tillich. Correlatio, v. 18, n. 1, p. 83-98, 2019.

PINHEIRO, Jorge. Teologia Socialista. Os caminhos humanos no pensamento de Tillich e Dussel. São Paulo: Fonte Editorial, 2017.

ROSA, Hartmut. Resonanz: Eine Soziologie der Weltbeziehung. Berlin: Suhrkamp, 2016.

STUMPF, João H.; DUMER, Pablo F. O suspiro manipulado do oprimido: reflexões a partir de Benjamin, Alves e Tillich. Correlatio, v. 17, n. 1, p. 47-62, 2018.

TILLICH, Paul. A Coragem de Ser. 2. ed. Trad.: Eglê Malheiros. Rio de Janeiro: Paz e Terra, 1972.

A Era Protestante. Trad.: Jaci Maraschin. São Paulo: Instituto Ecumênico de Pós-Graduação em Ciências da Religião, 1992.

Amor, Poder e Justiça: análises ontológicas e aplicações éticas. Trad.: Sérgio Paulo de Oliveira. São Paulo: Novo Século, 2004.

1974.

Dinâmica da Fé. Trad.: Walter Schlupp. São Leopoldo: Sinodal,

Teologia da Cultura. Trad.: Jaci Maraschin. São Paulo: Fonte Editorial, 2009.

Teologia Sistemática. 6. ed. rev. Trad.: Getúlio Bertelli, Geraldo Korndörfer. São Leopoldo: Sinodal; EST, 2011.

WESTHELLE, Vítor. O Deus escandaloso: o uso e abuso da cruz. Trad.: Geraldo Korndörfer. São Leopoldo: Sinodal; EST, 2008. 